\title{
A REVIRAVOLTA DO PENSAMENTO CRÍTICO NA CRIMINOLOGIA THE TURNABOUT OF CRITICAL THINKING IN CRIMINOLOGY
}

\section{Fábio Ataíde}

fabiusataide@hotmail.com

Mestre em Direito Constitucional pela Universidade Federal do Rio Grande do Norte (UFRN). Professor de Criminologia e Direito Penal da UFRN. Juiz de Direito.

\section{RESUMO}

O texto explora a mudança da criminologia crítica a partir dos seus primeiros movimentos teóricos. Tendo como referência o paradigma da reação, faz uma análise da superficialidade da teoria do labelling approach e desenvolve aspectos do aprofundamento que acontece com a criminologia crítica. Pretende mostrar como a crítica criminológica estruturou ferramentas para encontrar as raízes da criminalidade, rompendo com o mito da igualdade do Direito Penal, sem que seja possível explicar o crime a partir das deficiências sociais de uma única classe social ou com isenção para a criminologia estatal.

Palavras-chave: Labelling Approach. Criminologia Crítica. Paradigma da Reação.

\begin{abstract}
The text explores the change in critical criminology from its early theoretical movements. With reference to the paradigm of reaction, it analyzes the superficiality of the theory of labelling approach and develops deepening aspects of what happens to critical criminology. It aims to show how criminological critic structured tools for finding the roots of crime, breaking them with the myth of equality in criminal law, being not possible to explain the crime from the social deficiencies of a single social class or exemption for state criminology.
\end{abstract}

Keywords: Labelling Approach. Critical Criminology. Paradigm of Reaction.

\section{A NOVA CRIMINOLOGIA CRÍTICA}

O entendimento do crime somente se completa com o saber das inúmeras ciências que dele se ocupam, especialmente o Direito Penal e a Política Criminal, as quais, na história do Direito, já foram concebidas como ciências integradas à Criminologia (LISZT). Uma vez superada essa integração, não se pretende aqui levantar uma investigação que leve à defesa de como esse modelo integrado pode ser restaurado atualmente (BARATTA, 2004). Mesmo assim, não se deve deixar de ter em elevada conta o que previnem Figueiredo Dias e Manuel da Costa Andrade, quando escrevem que "fazer criminologia é, também, fazer injunções de ação dirigidas tanto aos agentes de aplicação das normas jurídico-penais ou aos seus destinatários individuais ou colectivos, como, em última instância, à própria sociedade"1. 
De tal modo, pretende-se levantar as injunções que a criminologia crítica dirige aos agentes da aplicação das normas jurídico-penais. Quais foram os impactos da criminologia crítica sobre o Direito? Como a criminologia crítica apresenta-se como uma questão nova para o mundo normativo e quais são as limitações desse mundo para a incorporação do paradigma da reação? Para refletir sobre essas questões, pensando apenas em começar a respondê-las, cabe ponderar a forma como, a partir da criminologia crítica, a explicação da criminalidade e da criminalização deixou marcadamente de ser domínio de uma teoria geral da criminalidade, meramente unifatorial.

Mudando o panorama de eficácia limitada da teoria do etiquetamento, restrita demais ao campo dos marginalizados, a criminologia crítica demarca-se pelo que se convencionou chamar "nova criminologia", movimento europeu cujos pioneiros foram Ian Taylor, Paul Walton e Jock Young. Esses autores destacam-se por apresentarem na obra New Criminology (1973) uma crítica às relações de poder fortemente marcadas pelo método marxista e pelo aprofundamento do paradigma da reação.

Certo de que o etiquetamento estimularia uma predisposição à falsa consciência de que somente alguns grupos desviantes transgrediriam, esses novos criminólogos críticos apontam o fracasso do etiquetamento na incapacidade para equacionar as questões da criminalidade dos poderosos e o mito da igualdade do Direito Penal. Tudo isso é de fundamental importância à Criminologia na América Latina, que, nas palavras de Jacinto Coutinho, não pode prescindir de um compromisso para com a libertação dos marginalizados e, nessa tarefa, o método dessa nova criminologia europeia se faz basilar na organização de uma estratégia transformadora de nossa realidade marginal, "principalmente no que diz respeito à criação de uma teoria materialista do desvio e à crítica ao mito do Direito Penal como direito igual"2.

A nova criminologia penetra mais no paradigma da reação ao denunciar a falta de compromisso da academia para com a efetiva libertação dos marginalizados. Segue a crítica feita por Gouldner, para quem o teórico do etiquetamento equipara-se ao guarda de zoológico, que, sem tomar partido claramente em favor do objeto, não faz nada para libertar os animais, ainda que diga protegê-los ${ }^{3}$.

De alguma forma, o positivismo criminológico assemelhou-se ao etiquetamento conferindo primazia à etiqueta como objeto de pesquisa. Mas convém deixar bem destacado que um diferiu do outro quanto à forma de sondar o problema: enquanto o positivismo biologista tomou superficialmente a etiqueta como um dado a-histórico, o labelling approach escava até reconhecer a temporalidade do processo de etiquetamento. É dizer, tendo na devida conta essas raízes do etiquetamento, a nova criminologia revoluciona ao regredir sua crítica a toda criminologia praticada até então e nessa revisão total extirpará o mais fino resquício do determinismo biologista, ainda fazendo entrar na crítica ao próprio determinismo da etiqueta praticado pelos teóricos do labelling approach. Em última análise, a nova criminologia agora deve fazer o que os teóricos do etiquetamento não puderam, ou seja, refletir o sistema de controle mais amplo, indo à raiz das suas dimensões do poder sem restringir a transgressão a uma questão de "empresários morais" etiquetadores ${ }^{4}$.

É um fato claro que Marx não desenvolveu nenhuma teoria criminológica, simplificadamente por acreditar que o criminoso, ao fazer parte do lupemproletariado, se tratava de um proletariado corrupto e desse modo não podia exercer um papel político revolucionário ${ }^{5}$. Isso mudará com a nova criminologia, para a qual o desvio deixa de ser um produto do etiquetamento e torna-se um ato de luta resultante de um processo dialético entre o indivíduo e a 
sociedade. É preciso dizer que, ao mudar o seu método de pesquisa para o materialismo histórico, a criminologia crítica passa a refletir agora a contribuição do modo de produção capitalista para a criminalização e isso exige, evidentemente, refutar o crime como um dado ontológico do positivismo e igualmente afastar a relativa superficialidade da explicação do etiquetamento.

A criminologia crítica irá aprofundar o exame dos órgãos de controle - já iniciado com o etiquetamento, mas agora investigando a sua relação com o modo de produção capitalista. Leva a efeito um projeto muito mais amplo, que se distanciará perigosamente do indivíduo criminoso, vigiado bem de perto pelo positivismo e, de certo modo, pela etiquetagem. A bem dizer, o Direito Penal será elevado à condição de ato político de dominação, de forma tal que o delinquente será encurralado a uma posição de defesa, a um ponto em que o seu crime cumprirá uma inquietante função de luta ou libertação - consciente ou não. Talvez não fosse preciso dizer que a nova criminologia vincula a teoria à pratica com o objetivo de transfigurar a criminologia em um programa para $\mathrm{o}$ futuro da sociedade. Em linhas gerais, inverte o programa positivista voltado a reconfigurar o futuro do indivíduo frente às necessidades da sociedade.

Isso será crucial para entender a criminologia crítica contemporânea no âmbito da América Latina, especialmente dando ênfase aos processos de luta e resistência na constituição do poder. Como esplendidamente coloca Cecília Coimbra, o "poder funciona, justamente, para responder aos movimentos de resistência". A relação de poder entre indivíduo e sociedade se constitui a partir da resistência e não propriamente do poder, ou seja, é a resistência que produz a relação de poder e não o contrário, não sendo mais adequado pensar aquela como consequência deste. E nessa nova perspectiva, resistir implica um ativismo inteiramente diferente, que implica a criação de novos valores, especialmente por meio de pequenas reações.

Seja como for, o método marxista chega à criminologia sem transformar a criminologia em marxista, mas abrindo reflexões a um determinismo baseado na patologia social e na ruptura do discurso oficial das ciências criminais. Isto indica que a aplicação desse método nos estudos criminológicos convida o pesquisador a rejeitar os discursos declarados em favor da busca pelas funções ocultas. Essa exigência está amplificada na dialética criminológica de Roberto Lyra Filho, para quem a legislação conserva em si a negação do Direito por meio dos interesses e caprichos do poder nela depositados ${ }^{7}$. Assim, podemos dizer que a função oficial de "ressocializar" da pena privativa de liberdade oculta de fato o papel não declarado de selecionar e segregar sujeitos vulneráveis em guetos.

\section{O SURGIR DE UMA NOVA CONSCIÊNCIA LIBERTADORA}

Nos anos 1960, houve uma virada na criminologia, com o surgimento da criminologia crítica. Nos Estados Unidos, o fortalecimento dos movimentos sociais traz novas demandas de libertação contra a opressão dos marginalizados tornando-se simbólico o início da moratória oficiosa à pena de morte a partir de 1967, o que cinco anos depois culminou com a declaração de inconstitucionalidade da pena capital pela Suprema Corte. O ambiente é de luta contra o patriarcado, racismo, homofobia e desemprego, não ficando de fora o encarceramento penal e a internação psiquiátrica (antipsiquiatria), e não somente isso. Diante da constatação de que Estados estavam matando mais do que ações individuais esses movimentos inspiram as lutas contra conflitos armados resultante de dis- 
putas imperialista. Estava claro ali que, na ordem dominante, havia uma classe superior servida com exclusividade pela criminologia conservadora.

A criminologia crítica desse período toma a classe dominante e seus benefícios na ordem capitalista como questão central. Ao instaurar, a partir do paradigma da reação, uma ruptura no discurso vigente de ordem, acaba por situar um olhar plural na luta por poder, como igualmente, o que é mais importante, legitima os valores dos vários grupos sociais em conflitos.

Para essa criminologia crítica já está evidente que todos podem ser transgressores, não havendo nenhuma razão para justificar o crime como exclusividade patológica de uma classe carente do Estado Social. Como escrevem Taylor, Walton e Young (1977) “em uma sociedade pluralística, todas as pessoas são potencialmente desviantes" ${ }^{8}$. Diante da inevitável crise do previdenciarismo/correcionalismo, o crime parece deixar de ser o problema que tinha sido porque a ordem dos discursos criminológicos instaura uma nova tensão crítica, agora abrindo fogo justamente contra aqueles que estavam imbuídos do controle da criminalidade. Essa criminologia crítica, causadora de "um mal-estar" nunca antes visto, transfere a questão problemática do controle da criminalidade para os grupos poderosos, ou seja, não se ocupa de um criminoso comum, mas de um sujeito que, por estar historicamente protegido pelas estruturas sociais, nunca se identificara com o criminoso.

A criminologia crítica teve o mérito de romper o modelo de saber acadêmico estabelecido predominantemente na ótica do opressor, fazendo com que o controle não fosse mais pensado exclusivamente na perspectiva de agentes punitivos, como juízes, policiais ou promotores de justiça. Instaura-se uma crítica à igualdade de oportunidades na sociedade por meio do método da dialética marxista, tanto diminuindo a importância da criminologia oficial do Estado e seu fetiche pelo criminoso comum, como promovendo uma nova consciência libertadora, sem o compromisso para com o discurso oficial da criminologia administrativa, "a libertação é o objetivo final de uma filosofia crítica da ordem legal"

\section{OS MUITOS OBJETOS DA CRÍTICA}

A eclosão de uma tamanha força crítica, inevitavelmente, prescindiu de uma preocupação com a definição precisa de um objeto. Enquanto a criminologia conservadora guardou-se bem centrada no crime e no criminoso, a criminologia crítica toma a própria escolha do objeto como um objeto de estudo. Sim, porque agora essa "escolha de eleitorado (de uma ampla série de grupos sociais existentes em situações de 'repressão normatizada') é um assunto para os próprios objetivos do teórico radical" ${ }^{\prime \prime}$. E essa possibilidade de criticar as próprias escolhas faz da criminologia crítica dinâmica e dinamizante, exatamente como pensa Zaffaroni (2013) sobre o Direito Penal fundado antropologicamente. Esse criminólogo latino abandona com isso o programa de uma ética geral para a sociedade e a ampla função pacificadora do Direito Penal, tornando-o um conhecimento em permanente ameaça por si mesmo. E por isso, insista-se, a proposta de Direito Penal antropologicamente fundado exige um saber penal que "deve ser dinâmico e dinamizante e estará sempre ameaçado em seu próprio dinamismo por forças"

Pois bem. Em última análise, o Direito Penal antropologicamente fundado, além de dinamizante, deve ser ele próprio dinâmico. É preciso assinalar que essa falta de um "eleitorado" prévio causa certamente muita imprecisão e abre muitas possibilidades para um romantismo criminológico, levando o 
criminoso comum a ser tratado como um herói. Fora esse risco, também cabe lembrar que essa dinâmica resultante da ausência de um campo muito específico de trabalho deixa o criminólogo liberado, inclusive, para o "saber parcial", muito longe da pretensa neutralidade científica da dogmática penal. Certo de que tampouco a crítica pode prescindir de ser ela própria objeto de outra crítica, a criminologia crítica abre-se a infindáveis objetos ou lugares nunca explorados pela pesquisa acadêmica.

Vou adiante para esclarecer que o crítico não mais toma as estatísticas com neutralidade. Com isso, a pesquisa dos dados empíricos não deixa - e nem pode - de ser um caminho, mas não será mais do que um caminho. Assim, enquanto o teórico conservador preocupa-se em aperfeiçoar o sistema repressivo, a partir de uma análise mais complacente dos dados empíricos, o criminólogo crítico desconfiará dos próprios dados, questionando as desigualdades encontradas em busca de mudanças, mas não qualquer mudança. Está atrás de uma reforma capaz de suplantar as desigualdades para constituir uma justiça penal em que o humano prevaleça. Na mesma linha do Direito Penal antropologicamente fundamentado Zaffaroni $(2012 ; 2013)$, Taylor, Walton e Young (1977) advertem que "a tarefa não é, simplesmente, catalogar desigualdades, mas criar análises empiricamente fundadas que apontem o modo de superar a desigualdade, em direção a uma sociedade genuinamente justa e humana" ${ }^{\prime \prime}$.

Nessa tentativa de iniciar a crítica, essa utilização de explicações didáticas não encerra a complexidade da questão. Para ir mais fundo, Vera Regina toma o saber penal como essencialmente fundado em uma dogmática manualística, em cujo centro está a descrição abstrata de um poder punitivo nos domínios limitados da lei. A ampla construção do saber daí decorrente descreve a abstração de um jus puniendi apenas em torno dos crimes e suas penas, que surgem nesse caso inteiramente despolitizados e neutros. A despeito de estar enfronhando na política, o poder punitivo termina seus dias racionalizando a forma como o Estado lida com o crime a partir dessa redução estritamente legal ${ }^{13}$.

Inexistem conflitos sociais na lei, sobretudo na Constituição, onde comumente prevalece outra realidade. Por isso, em linhas gerais o rol de direitos individuais da Constituição de 1988 está semelhante ao da Constituição do Império e nem por isso podemos acreditar que se assemelham as realidades dos dois períodos. No art. 179, item 18, da Constituição imperial já havia uma providência para que fosse organizada o quanto antes um "código criminal, fundado nas sólidas bases da justiça e equidade", exigência cuja validade ainda continua em vigor.

Assim, a partir do paradigma da reação, a crítica criminológica toma como marco teórico revisar aquilo que "desde disciplinas como a História, a Historiografia, a Teoria política, a Sociologia, Economia política e a Economia política da pena já havia sido reconhecido há quase um século: a politicidade do mecanismo punitivo"14. Restituindo à pena o seu caráter político, estaremos prontos para redefinir os mecanismos punitivos, especialmente reconhecendo a participação do "garantismo" na violação de direitos humanos dos condenados e ainda dos agentes que operam o sistema, abrindo na América Latina uma deslegitimação profunda, que ocorre desde a própria teoria até à constatação empírica da realidade.

Como adverte Vera Regina, bem situada na linha de Zaffaroni, a criminologia não se trata de uma ciência, mas de um "saber proveniente de múltiplos ramos", assim estruturado com o propósito maior de conter a violência e não produzi-la, ou seja, cumpre a este saber o dever em última instância de salvar vidas, o que exige revisar o garantismo abstrato baseado numa dogmática difun- 
dida em incontáveis ramos, mas todos conectados ao mito da unidade judiciária. Como continua a professora, esse mito faz crer existir um judiciário singular, quando de fato deveria ser pensado no plural, como entidade gigantesca, comunicando-se e cumprindo funções com os muitos órgãos que formam o sistema de controle formal e informal. Mais difícil é perceber que o gigante está assentado por meio de um paradoxo que o leva a ser o distribuidor da cidadania de um lado e, por outro, o responsável pelos processos de criminalização ${ }^{15}$.

Essa mesma temática está profundamente explorada por Haroldo Abreu. Na moderna sociedade burguesa, os homens realçaram drasticamente suas capacidades individuais, de tal modo que indivíduo e sociedade se distanciam, sendo esta separação a principal e mais notável característica do pensamento burguês liberal. De um lado, o homem com a propriedade de si mesmo, atomizado, abstratamente igual a todos os outros, isto é, o indivíduo está pensado fora do seu lugar. Para esse autor, o que resta é a imagem abstrata de uma igualdade de todos como "senhores de si e de suas ações"16.

Tudo isso tem um reflexo direto no campo penal, de tal modo que, sem esquecer as amplas reflexões de Haroldo Abreu, podemos dizer que a prisão no sistema capitalista tornou-se o lugar reservado com exclusividade para ocultar a desigualdade, esconder os que não conseguiram alcançar os objetos simbólicos e materiais da cidadania. De fato, a prisão é o lugar sem honra para os que perderam a luta pela mercadoria, o espaço de derrota do homo economicus legalis. $\mathrm{Na}$ perspectiva do mal-estar dualizado, Abreu avança dizendo que "o homem tem uma dupla face, econômica, consumidora e de outro uma identificação jurídica carente de proteção em suas relações sociais" ${ }^{17}$.

Portanto, é preciso investigar o papel das agências penais na seleção do sujeito atomizado que não conseguiu cumprir o ideal consumidor e como as agências penais usam os meios de coerção para afirmar as exigências do sistema capitalista, sob o discurso universal de direitos humanos.

Essa situação dramática atrai muitas questões. A judicialização da cidadania marca uma pauta social para as demandas da justiça, enquanto também contradiz a operacionalização seletiva desse poder no âmbito criminal. Ora, como complementa Vera Regina Andrade (2012), o antagonismo se agrava porque a pauta da cidadania prescreve emancipação, direitos civis, igualdade material, tolerância e inclusão, ou seja, prometendo o inverso do que marca o sistema penal e seu programa criminal baseado em limitação de direitos e liberdades, seletividade, exclusão, marginalização, reprodução da violência e desigualdades ${ }^{18}$.

Essa maximização do Estado penal acaba engolindo e minimizando o Estado social, levando a cabo um processo de genocídio, oculto na proposta garantista e impulsionado por um crescente reformismo legitimante legislativo que canaliza os conflitos sociais à solução judicializada. Ignora-se por completo a incapacidade da lei de resolver problemas cujas origens estão nas estruturas deficitárias da própria vida moderna ${ }^{19}$.

\section{A EXCLUSÃO NA SOCIEDADE PÓS-FORDISTA}

É necessário destacar que a criminologia crítica incorpora do funcionalismo a diferença entre funções aparentes e ocultas. Como acerta Larrauri, o termo nova criminologia é uma ironia, porque não há nada de novo em tratar das relações históricas de poder e tomar o método marxista como meio para 
pesquisa; essa nova criminologia seria de fato uma criminologia que já nasce velha e, embora embebida num método marxista, não se torna uma criminologia marxista, principalmente tomando os desinteresses de Marx pelo tema ${ }^{20}$.

Muitos dos postulados da nova criminologia vieram a ser revisados, mas em linhas gerais permanecem adequados a uma reflexão criminológica marginal na América Latina. De algum modo, ainda que não seja recomendável reduzir essas propostas a um esquema fechado, podemos reconhecer que a nova criminologia realça como característica (1) a existência de uma classe dominante no governo social; (2) a interferência desses interesses dominantes na produção do Direito Penal; (3) a redução dos órgãos de controle à proteção bens jurídicos de interesse dessa classe; (4) o delito como produto de uma relação de luta entre classes e (5) a desproporcionalidade das sanções aplicadas entre as diferentes classes. De fato, é preciso não terminar o esboço da nova criminologia apenas com esses poucos aspectos, sob efeito de acabar por cair em um determinismo econômico perigoso ${ }^{21}$. Porém, nem por isso podemos deixar de aceitar que os aportes da nova criminologia aplicam-se à realidade latina, a qual, segundo Juarez Cirino, estaria assinalada pela "repressão impiedosa das classes dominadas", o "terror institucionalizado" e "a imunidade das classes dominantes"22.

Isso não implica dizer que a luta de classe continua como antes e nem que a criminologia conservadora seja uma mera interferência punitiva de uma classe dominante sobre os interesses de uma população subjugada; parece restrito demais pensar os órgãos de controle assim estruturados para a defesa incondicional de bens jurídicos exclusivamente de uma única classe dominante. De fato, o delito tornou-se produto de um jogo de poder muito mais complexo, porém, que no final das contas continua resumido à desproporcionalidade nas sanções aplicadas aos diferentes sujeitos sociais.

$\mathrm{Na}$ sociedade tardia, valores de mercado coexistem com muitos outros para além dos interesses meramente econômicos. Assim, temas como os relacionados à sociedade de risco, à proteção ambiental ou à discussão de gênero passam a integrar a pauta do Direito Penal, tornando impossível sintetizar a criminologia a partir de uma luta maniqueísta entre a classe dominante e a dominada.

Como afirma Young (2002), a crise econômica no início da década de 1970 teria apressado o surgimento de um Estado Penal movido por uma "dialética da exclusão", decorrente de um impasse entre o indivíduo massificado e a projeção da diversidade. A sociedade consensual, moldada para o sujeito treinado, massificado, conformado e disciplinado a um tipo de conduta, serviu aos interesses de um modelo de produção fordista. No pós-fordismo, essa realidade dá lugar à sociedade excludente, agora deslocada para a exacerbação do individualismo e elevação dos níveis de desconfiança, riscos e insegurança. Em função disso, o Direito Penal aparece como importante ferramenta para cumprir a finalidade de excluir o outro ${ }^{23}$, ficando fácil assim perceber as causas da falta de funcionalidade do conceito ressocializador na teoria da pena, porque, como escreve Pavarini nessa mesma perspectiva, "o crescimento da multidão dos politicamente excluídos torna irrealista o projeto de uma ordem social inclusiva" ${ }^{24}$. 


\section{A CRIMINOLOGIA MIDIÁTICA COMO OBSTÁCULO À CRÍTICA CRIMINOLÓGICA: GUERRA CONTRA O CRIME NO CONTEXTO MIDIÁTICO}

Na sociedade pós-fordista, a construção do que se entende por política de segurança começa a partir da imagem alimentada midiaticamente de uma guerra contra o crime. À luz de um conflito urbano em andamento, a ocupação de novos territórios é festejada como uma batalha vencida e assim patrulhas rotineiras nas zonas "sob controle inimigo" revelam muitos aspectos dessa política de segurança, certamente estruturada à atuação seletiva contra marginalizados.

Essa política de segurança funda-se no direito à segurança, constitucionalmente regulador da segurança pública como um dever do Estado e direito de todos, a ser exercido, nos termos do art. 144/CF, "para a preservação da ordem pública e da incolumidade das pessoas e do patrimônio". Esta aparente a escolha constitucional por uma política de segurança vaga, sem limites à atuação policial contra os marginalizados (ordem pública) e, o que é pior, em benefício das classes mais abastadas (proteção do patrimônio). Diante do predomínio do modelo de política de segurança, Baratta assinala os equívocos na percepção da segurança como um único direito, impedindo que se tenha a compreensão da segurança de todos os direitos, ou seja, que se compreenda a segurança no contexto de política integral de direitos fundamentais ${ }^{25}$.

O espetáculo midiático progride à custa de uma ignorância nutrida diariamente pelos meios de comunicação, que fazem do cidadão um consumidor compulsivo de bens e da polícia um ator da ideologia da Defesa Social, ignorando quase que completamente o fenômeno crime como uma questão inerente a todos os estratos sociais (SUTHERLAND). Essa ideologia da Defesa Social, cujas bases remontam a Escola Clássica, transformam as antigas teorias de explicação da criminalidade em estratégia de combate, norteada por princípios que partem das seguintes conclusões: (1) indicação do Estado como representante maior dos interesses da sociedade; (2) o delinquente como um sujeito disfuncional à sociedade; (3) expressão do crime como uma conduta voluntária negativa dos interesses sociais superiores; (4) a crença de que a pena seria capaz de garantir o regresso do indivíduo ao bom convívio social; (5) o Direito Penal como instância igualitária a qual todos estão sujeitos; e (6) o crime como impeditivo das condições mínimas de vida em sociedade ${ }^{26}$.

Diante de uma sociedade com medo e de uma mídia indecisa, que tanto critica a impunidade como a ação invasiva das instâncias de controle, mas que, no final das contas, reproduz a ideologia da Defesa Social, fica mantido um consenso em torno da política de segurança e do papel da polícia como reprodutor legítimo da violência contra as classes perigosas. Se pararmos para pensar, perceberemos que a criminologia midiática opera sobre o funcionamento dos controles punitivos, batendo com mais ênfase na tecla que reforça o estranhamento dos marginalizados, contra os quais justificamos a ação da polícia como protetora da segurança "dos direitos da maioria".

Nessa guerra contra o crime, a política como espetáculo (Baratta) precisa de muitas mortes de estranhos, contabilizadas diariamente pelos meios de comunicação. Como explica Zaffaroni (2012, p. 311), o cadáver da vítima se confunde com o do inimigo morto; aquilo que seria um ato de violência se constitui assim em uma necessidade de limpeza social ${ }^{27}$. No entanto, quando a ação policial recai sobre um dos "nossos", atingindo um "trabalhador" ou quem não se identifica com o "estereótipo marginalizado", saímos em busca de expiação. Sob pressão midiática, a ação dos controles será rápida, muitas vezes 
com autoridades noticiando o sumário afastamento dos policiais envolvidos. As agências de controle se retraem por um curto espaço de tempo para entregar o policial como um bode expiatório à vingança coletiva.

Podemos afirmar que a criminologia midiática se interpõe como obstáculo ao discurso criminológico crítico, tanto quanto assume para si a função de dosador da proporção e intensidade de funcionamento do sistema de controle, como também quando critica a ação punitiva das agências de controle. Ela faz jogo duplo por discursos de ação e retração, tornados em muitos casos fundamentos para a desproporcionalidade das sanções penais.

Sobre o conflito entre criminologia midiática e poder punitivo, são precisas as palavras de Zaffaroni (2012, p. 312):

"A criminologia midiática entra em conflito quando o poder punitivo
comete um erro e vitimiza alguém que claramente não pode ser iden-
tificado com eles e, na qualidade de vítima, não se lhe poderia negar
espaço midiático. É o colateral damageda guerra contra o crime. Nes-
ses casos inevitáveis, as agências entregam ao executor material para
acalmar a onda midiática e, desse modo, aproveitam para demonstrar
que expurgam elementos indesejáveis. Na realidade, entregam a poli-
ciais oriundos de um setor social humilde que foi treinado com singular
negligência para fazer isso e que sabe que chegou sua vez de perder." 28

Mais difícil ainda é tomar consciência de que, mesmo quando os controles punitivos operam contra a ação violenta dos policiais, podemos estar diante de mais um espetáculo de guerra, que desvia nossa atenção à culpa de um único policial desviante. Até parece que esse mesmo policial não faz parte de um sistema e que pouco tempo atrás estava do nosso lado na execução da ideologia da Defesa Social.

\section{CONCLUSÃO}

Pretendo resumir toda essa discussão a partir de uma analogia com uma descoberta de cineasta alemão Werner Herzog. Quando criança, ele desvendou-se para o cinema a partir de uma revelação, quando em um filme viu a mesma cena repetida em dois momentos distintos. Assim, em um baque de consciência, entendeu que tudo aquilo não era realidade, mas pura armação. Como Herzog, o movimento teórico da nova criminologia percebe a insídia das cenas sociais, deixando descoberta uma nova realidade das estruturas normativas de controle da violência.

Contudo, não foi a teoria do etiquetamento que conseguiu romper definitivamente o mito da igualdade do Direito Penal e tampouco dispôs o criminólogo de ferramentas suficientemente adequadas para revisar toda a criminologia. Efetivamente, é a criminologia crítica que vai ao encontro das raízes e das diferenças dialéticas entre sociedade e indivíduo, para assim ajustar a relação entre transgressão e o modo de produção capitalista.

Dotou dessa forma o criminólogo de instrumentos para lutar e resistir de uma forma inteiramente nova. Nova porque os discursos legais serão vistos como parte de uma cena repetida na história, de uma armação para os olhos, cabendo à criminologia descobrir onde e como a dominação se repete, sendo tudo isso necessário para compreender a América Latina e uma criminologia que venha dizer-se marginal. 
A partir dos anos 1960, o ambiente de luta rompe o discurso vigente de ordem, situando um olhar plural na luta por poder, como também legitimando os valores dos vários grupos sociais em conflito. Chega ao fim os tempos de crime como exclusividade de uma underclass. Uma vez desviada a crítica para os próprios órgãos de controle, anulando a criminologia oficial do Estado, surge uma nova consciência crítica, que não deixa de fora nem a própria escolha dos objetos que devem ser criticados.

Portanto, fica sem sentido prático a descrição abstrata de um poder punitivo limitado aos domínios da lei. O reconhecimento dessa politicidade do mecanismo punitivo (ANDRADE, 2012) mostra como o sistema penal funciona ocultando a violência estrutural e o quanto fomenta a criminalidade ao produzir subjetividades marcadas por indivíduos reduzidos ao projeto de consumo. Seja como for, a emancipação da cidadania não alcança o sistema penal, em que prevalece a maximização do Estado penal, abrindo portas para um processo de genocídio, oculto, mas muito bem presente.

Diante desse quadro, impõe entender a dramaticidade da política de segurança na América Latina, em que o espetáculo midiático reforça a ideologia da Defesa Social e apressa saídas legislativas tomadas em momento de medo e indecisão. Mesmo fazendo jogo duplo por meio de discursos muitas vezes contraditórios, a criminologia midiática funciona sobre os controles punitivos e se interpõe como obstáculo ao desenvolvimento do discurso criminológico crítico.

\section{NOTAS}

${ }^{1}$ DIAS, Jorge de Figueiredo; ANDRADE, Manuel da Costa. Criminologia: o homem delinquente e a sociedade criminôgena. Coimbra: Coimbra Editora, s.d., p. 98.

${ }^{2}$ COUTINHO, Jacinto Nelson de Miranda; MARQUES, Allana Campos. Baratta: Aldilá do sistema penal. In: ANDRADE, Vera Regina Pereira de (Org.). Verso e reverso docontro/epena: (des)aprisionando a sociedade da cultura punitiva. Florianópolis: Boiteux, 2002, v. 1, p. 110-111, apud ANDRADE, Vera Regina Pereira de. Pelas mãos da criminologia: o controle penal para além da (des)Ilusão. Rio de Janeiro: Revan; ICC. 2012 (Pensamento criminológico; 19), p. 114.

${ }^{3}$ LARRAURI, Elena. Criminología y Derecho: la herencia de la criminología crítica. 3. ed., Madrid: Siglo Veintiuno de España Editores, 2000, p. 106.

${ }^{4}$ Ibid, p. 108.

${ }^{5}$ TAYLOR, IAN; WALTON, Paul; YOUNG, Jock. La nueva criminologia: Contribución a una teoria social de la conducta desviada. Trad. Adolfo Crosa, Buenos Aires: Amorrortu editores, 1977 (primeira edição em inglês de 1975), p. 14.

${ }^{6}$ COIMBRA, Cecília Maria Bouças. Modalidades de Aprisionamento: processos de subjetivação contemporâneos e poder punitivo. In: ABRAMOVAY, Pedro Vieira; BATISTA, Vera Malaguti (Org.). Seminário depois do grande encarceramento. Rio de Janeiro: Revan, 2010, p. 190.

${ }^{7}$ LYRA FILHO, Roberto. O que é Direito. 17. ed., São Paulo: Brasiliense, 2006 [Coleção Primeiros Passos, 62], p. 8.

${ }^{8}$ TAYLOR, Ian; YOUNG, Jock; WALTON, Paul (Orgs.). Criminologia crítica. Trad. Juarez Cirino dos Santos e Sérgio Tancredo. Rio de Janeiro: Graal, 1980, p. 78.

${ }^{9}$ Ibid, p. 235.

${ }^{10}$ Ibid, p. 32.

${ }^{11}$ ZAFFARONI, Eugenio Raúl; PIERANGELI, José Henrique. Manual de Direito Penal Brasileiro. Volume I, parte geral, 10. ed. São Paulo: Editora Revista dos Tribunais, 2013, p. 338.

${ }^{12}$ TAYLOR, Ian; YOUNG, Jock; WALTON, Paul. (Orgs.). Criminologia crítica. Trad. Juarez Cirino dos Santos e Sérgio Tancredo. Rio de Janeiro: Graal, 1980, p. 54.

${ }^{13}$ ANDRADE, Vera Regina Pereira de. Pelas mãos da criminologia: o controle penal 
para além da (des)Ilusão. Rio de Janeiro: Revan; ICC. 2012 (Pensamento criminológico; 19), p. 234.

${ }^{14}$ Ibid, p. 240.

${ }^{15}$ Ibid, p. 246.

${ }^{16}$ ABREU, Haroldo. Para além dos direitos: cidadania e hegemonia no mundo moderno. Rio de Janeiro: UFRJ, 2008, p. 36.

${ }^{17}$ Ibid, p. 43.

${ }^{18}$ ANDRADE, Vera Regina Pereira de. Pelas mãos da criminologia: o controle penal para além da (des)Ilusão. Rio de Janeiro: Revan; ICC. 2012 (Pensamento criminológico; 19), p. 246.

${ }^{19}$ Ibid, p. 250.

${ }^{20}$ LARRAURI, Elena. Criminología y Derecho: la herencia de la criminología crítica. 3. ed., Madrid: Siglo Veintiuno de España Editores, 2000, pp. 16 e 117.

${ }^{21}$ Ibid, p. 118-9.

${ }^{22}$ SANTOS, Juarez Cirino dos. As raízes do crime. Um estudo sobre as estruturas e as instituições da violência. Rio de Janeiro: Forense, 1984. p. 70-71, apud ANDRADE, Vera Regina Pereira de. Pelas mãos da criminologia: o controle penal para além da (des)Ilusão. Rio de Janeiro: Revan; ICC. 2012 (Pensamento criminológico; 19), p. 103.

${ }^{23}$ YOUNG, Jock. A sociedade excludente: exclusão social, criminalidade e diferença na modernidade recente. Trad. de Renato Aguiar. Rio de Janeiro: Revan, Instituto Carioca de Criminologia, 2002 (coleção pensamento criminológico, n. 7), p. 23.

${ }^{24}$ PAVARINI, Massimo. O Encarceramento de Massa. In: ABRAMOVAY, Pedro Vieira; BATISTA, Vera Malaguti. (Org.). Seminário depois do grande encarceramento. Rio de Janeiro: Revan, 2010, p. 307.

${ }^{25}$ BARATTA, Alessandro. Criminología Y Sistema Penal (Compilación in memoriam). Montevideo - Buenos Aires: Julio César Faira - Editor, 2004, p. 203.

${ }^{26}$ Ibid, pp. 36-7.

${ }^{27}$ ZAFFARONI, Eugenio Raúl. A palavra dos mortos: conferências de criminologia cautelar. Coordenação de Luiz Flávio Gomes e Alice Bianchini. São Paulo: Saraiva, 2012, p. 311.

${ }^{28}$ Ibid, p. 312.

\section{REFERÊNCIAS}

ABRAMOVAY, Pedro Vieira; BATISTA, Vera Malaguti. (Org.). Seminário depois do grande encarceramento. Rio de Janeiro: Revan, 2010.

ABREU, Haroldo. Para além dos direitos: cidadania e hegemonia no mundo moderno. Rio de Janeiro: UFRJ, 2008.

ANDRADE, Vera Regina Pereira de. Pelas mãos da criminologia: o controle penal para além da (des)Ilusão. Rio de Janeiro: Revan; ICC. 2012 (Pensamento criminológico; 19).

DIAS, Jorge de Figueiredo; ANDRADE, Manuel da Costa. Criminologia: o homem delinquente e a sociedade criminôgena. Coimbra: Coimbra Editora, s.d., p. 98 .

BARATTA, Alessandro. Criminología y sistema penal (compilación in memoriam). Montevideo - Buenos Aires: Julio César Faira - Editor, 2004.

. Criminología crítica y crítica del derecho penal: introducción a la sociología jurídico penal.- Buenos Aires: Siglo XXI Editores Argentina, 2004.

LARRAURI, Elena. Criminología y derecho: la herencia de la criminología crítica. 3. ed., Madrid: Siglo Veintiuno de España Editores, 2000. 
LYRA FILHO, Roberto. O que é Direito? 17. ed., São Paulo: Brasiliense, 2006 [Coleção Primeiros Passos, 62].

TAYLOR, Ian; WALTON, Paul; YOUNG, Jock. La nueva criminologia: contribución a una teoria social de la conducta desviada. Trad. Adolfo Crosa, Buenos Aires: Amorrortu editores, 1977 (primeira edição em inglês de 1975).

. (Orgs.). Criminologia crítica. Trad. Juarez Cirino dos Santos e Sérgio Tancredo. Rio de Janeiro: Graal, 1980.

YOUNG, Jock. A sociedade excludente: exclusão social, criminalidade e diferença na modernidade recente. Trad. de Renato Aguiar. Rio de Janeiro: Revan, Instituto Carioca de Criminologia, 2002 (coleção pensamento criminológico, n. 7).

ZAFFARONI, Eugenio Raúl; PIERANGELI, José Henrique. Manual de Direito Penal Brasileiro. Volume I, parte geral, 10. ed. São Paulo: Revista dos Tribunais, 2013.

. A Palavra dos Mortos: conferências de criminologia cautelar. Coordenação de Luiz Flávio Gomes e Alice Bianchini. São Paulo: Saraiva, 2012. 